\title{
Optimum Allocation of MR Dampers within Semi-Active Control Strategies of Three-Degree- of-Freedom Systems
}

\author{
https://doi.org/10.3991/ijes.v4i4.6546 \\ O.M.M. Elmeligy and M.H.M. Hassan \\ British University in Egypt (BUE), Cairo, Egypt
}

\begin{abstract}
Smart structural control is now emerging as an alternative to conventional earthquake resistant design and traditional structural control techniques. Fuzzy logic based control is one of the promising smart control strategies that could be used for this function. Magneto Rheological (MR) dampers are considered one of the promising semi-active control devices that can be used to control the structural response of buildings under earthquake excitation. The properties of MR dampers can be controlled using several smart techniques such as Fuzzy Logic.
\end{abstract}

In this paper, a comparative analysis is conducted to investigate the most optimum location for placing MR dampers, which are controlled by Fuzzy Logic, in a three-degree-offreedom benchmark problem. The study explores three potential schemes for allocating and operating MR dampers within the system under consideration. Two main structural response parameters are considered in this study, maximum displacement and maximum acceleration. In addition, the study investigates the lowest number of fuzzy-controlled MR dampers that are required in order to produce the required structural behaviour. This is an initial step towards the development of a generic allocation algorithm that is capable of identifying the required number of MR dampers, and their location, for controlling any multidegree-of-freedom system.

Index Terms-Structural Control, Structural Dynamics, Smart Structures, MR Dampers and Fuzzy Control.

\section{INTRODUCTION}

Traditionally, structures are designed to be able to resist dynamic loads with enough ductility to ensure the ability of structures to retain its strength under severe loading conditions and provide enough warning before failure. This concept has two main disadvantages as follows [1]:

1-Structures depend on their constant small damping ability to dissipate the earthquake energy with no welldefined guidelines to be able to improve the damping properties of commonly used materials in construction.

2-Structures depend mainly on their stiffness to resist loads which is an uneconomic solution.

Therefore, researchers were motivated to improve design methodologies and thus, the behaviour of structures. This includes the conducted research to propose different structural control strategies which can be used to reduce structural response under earthquake excitation. Magneto rheological (MR) dampers are one of the promising devices that can be used in structural response control; they are dampers filled with a smart fluid known as Magneto rheological (MR) fluid whose properties can be controlled by varying the applied voltage to the damper [2, 3, 4]. The calculation of the required voltage can be done by several control techniques such as fuzzy control [5].

Based on previously conducted research $[3,6,7,8]$, it is found that few researchers have investigated the use of fuzzy control for controlling Multi-Degree-of-Freedom (MDOF) systems using multiple MR dampers. In addition, this few conducted research studied cases with specific arrangements of MR dampers that cannot be generalized to other structural systems. In this paper, a comparative analysis is conducted to investigate the most optimum location for placing MR dampers, which are controlled by Fuzzy Logic, in a three-degree-of-freedom benchmark problem. The study explores three potential schemes for allocating and operating MR dampers within the system under consideration. Two main structural response parameters are considered in this study, maximum displacement and maximum acceleration. In addition, the study investigates the lowest number of fuzzy-controlled MR dampers that are required in order to produce the required structural behaviour.

\section{BENCHMARK PROBLEM AND DAMPERS CONFIGURATION}

A benchmark problem is a standard structural system that can be used in research conducted by different groups to facilitate the ability to compare different results of several control strategies by excluding other factors affecting the behaviour such as dimensions, sections and seismic masses. Structural systems subjected to earthquake excitation can be modelled as follows [9]:

$$
\boldsymbol{M} \ddot{\boldsymbol{u}}+\boldsymbol{C} \dot{\boldsymbol{u}}+\boldsymbol{K u}=-\boldsymbol{m} \ddot{u}_{g}+\boldsymbol{F}_{\boldsymbol{d}}
$$

Where:

- $\mathrm{M}$ is a $3 \times 3$ mass matrix

- $\mathrm{C}$ is a $3 \times 3$ damping matrix

- $\mathrm{K}$ is stiffness matrix

- $\ddot{\mathbf{u}}$ is acceleration vector

- $\dot{\mathbf{u}}$ is relative velocity vector to the ground

- $\mathbf{u}$ is relative displacement vector to the ground

- $\ddot{\mathbf{u}}_{\mathrm{g}}$ is the ground acceleration.

- $\mathbf{F}_{\mathbf{d}}$ is dampers force vector. 
Figure 1 outlines a general configuration of the benchmark problem along with the dampers configuration. In general, the control system works by measuring the structural response using a group of sensors. This data is then received by the processor which may include other fuzzy components in addition to the fuzzy controller. The processor calculates the required voltage for each damper; these dampers will adjust their characteristics to result in a targeted structural response.

The structural parameters of the used benchmark can be expressed as follows [10]:

$$
\begin{gathered}
\boldsymbol{M}=\left[\begin{array}{ccc}
98.3 & 0 & 0 \\
0 & 98.3 & 0 \\
0 & 0 & 98.3
\end{array}\right] \mathrm{kg}, \\
\boldsymbol{C}=\left[\begin{array}{ccc}
175 & -50 & 0 \\
-50 & 100 & -50 \\
0 & -50 & 50
\end{array}\right] \frac{\mathrm{N} \mathrm{sec}}{\mathrm{m}} \\
\& \boldsymbol{K}=\left[\begin{array}{ccc}
12 & -6.84 & 0 \\
-6.84 & 13.7 & -68.4 \\
0 & -6.84 & 68.4
\end{array}\right] 10^{5} \mathrm{~N} / \mathrm{m}
\end{gathered}
$$

In order to calculate the force generated by an MR damper, it is required to use one of the models available in the literature. The most widely accepted model, used in civil engineering applications, is based on Bouc-Wen Model which can be expressed as follows $[2,4]$ :

$$
\begin{aligned}
& R^{j} \text { : If } x_{1} \text { is } A_{1}^{j} \text { and } x_{\mathrm{p}} \text { is } A_{\mathrm{p}}^{j} \text { then } y_{1} \text { is } B_{1}^{j} \text { and } y_{\mathrm{m}} \text { is } B_{\mathrm{m}}^{j} \\
\dot{z} & =-\gamma|\dot{x}-\dot{y}| z|z|^{n-1}-\beta(\dot{x}-\dot{y})|z|^{n}+A(\dot{x}-\dot{y}) \\
\dot{y} & =\frac{1}{c_{o}+c_{1}}\left(\alpha z+c_{o} \dot{x}+k_{0}(x-y)\right) \\
F & =c_{1} \dot{y}+k_{1}\left(x-x_{0}\right)
\end{aligned}
$$

Where:

- $\mathrm{k}_{1}$ is the stiffness of the accumulator.

- $\mathrm{c}_{\mathrm{o}}$ is damping at large velocity.

- $\mathrm{c}_{1}$ is damping at lower velocities.

- $\mathrm{x}_{\mathrm{o}}$ is the initial displacement representing the accumulator.

- $\mathrm{k}_{\mathrm{o}}$ is the stiffness at larger velocities.

- $\mathrm{F}$ is the force generated by the damper

The previous equations have several parameters that depend on the specific used damper; $\gamma, \beta, A, \alpha, c_{0}, c_{1}$ which should be tuned to reflect the damper behaviour. $\mathrm{k}_{1}$, $\mathrm{k}_{\mathrm{o}}$ and $\mathrm{x}_{\mathrm{o}}$ depend on the damper specifications. For the 3000-N MR dampers, which are used in this paper, these parameters were given by Spencer et al. [2]

The process of controlling MR dampers is meant to determine the voltage required to be applied to the damper, based on the system response, to change the properties of the MR fluid to improve the system's behaviour. The problem here lies in the fact that the relation between the electric current applied to the damper and the force generated by the damper is nonlinear; therefore, it has always been an important point of research to develop effective control strategies to calculate the electric current or voltage to be able to obtain full usage of MR dampers. The use of fuzzy logic is one of the promising control techniques that can be used in this regard [11].

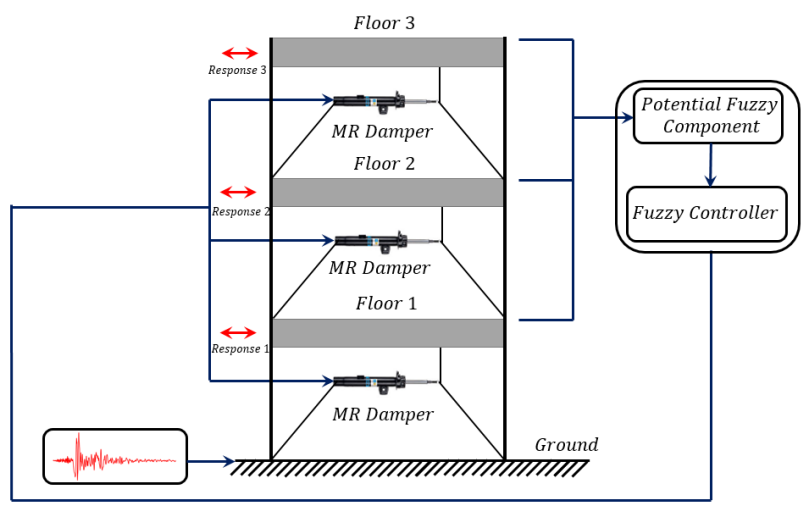

Figure 1. A schematic diagram for the modelled system.

\section{FUZZY CONTROLLER DESIGN}

Linguistically, "fuzziness" can be defined to be the opposite of "precision". Fuzziness includes using different degrees of truth instead of having only two extreme conditions representing the exactly true or exactly false events; this can help greatly in the intelligent control of robots and other engineering systems. The concept of fuzzy logic is to map inputs to outputs through a set of "if-then" rules that comprises a rule base; this process is known as fuzzy inference. All of these rules are normally evaluated in parallel with the order of evaluation being not important. These rules are described in a linguistic form with inputs and outputs defined with a range for each one in the form of a membership function; inputs are known as "antecedents" while outputs are known as "consequents". The complexity of the formulation of these rules increases as the complexity of the system increases; this requires full understanding of the behaviour of the system and proper testing of the system to ensure that acceptable results are obtained (Gomes, 2012). If-then rules take the following form:

Where: "xi" is an input, "yi" is an output, "A" and "B" are fuzzy sets.

Fuzzy inference process is one of mapping inputs to the required outputs using fuzzy logic. This process has predefined procedures as follows (Gomes, 2012):

1- Fuzzification of Crisp Inputs: this process includes determining the degree to which each input belongs to a relevant fuzzy set using membership functions. In this stage, the crisp (definite) input will be changed to linguistic variable with a specific membership value (0 to 1$)$ for each available set, which will represent antecedents for ifthen rules, later.

2- Applying Fuzzy Operators to Linguistic Input: this is applicable if the rule has more than one input since it is required to obtain one value for the membership function to be applied to the output of this rule. "AND" and "OR" are two of the widely used operators. For the used fuzzy method in this research, AND is used to take the smallest membership function value of inputs while OR is used to take the largest membership function values of outputs. The obtained value will be applied to the output as will be indicated later.

3- Implication: it is the process of using the calculated membership functions of the inputs after applying the chosen fuzzy operator to be applied to the outputs (known as consequents). The produced output can be considered as truncated sets; the truncation value is based 
on the value of the membership function after the application of the operators.

4- Aggregation: it is the process of combining the outputs of the fired rules together, which are the rules with the problem inputs belonging to their input sets, to get only one output represented by only one fuzzy set.

5- Defuzzification: it is the process of getting a crisp (definite) value using the fuzzy set resulting from the aggregation process. The most popular method is the centroid method where the crisp value is considered to be the centre of area of the fuzzy set.

The proposed design is based on allocating a separate fuzzy controller for each damper used in the system. In order to incorporate the interaction between consecutive floors, relative responses between floors are used as inputs for each controller. For example, to control the damper placed between the second and third levels, the relative displacement and velocity of these floors, with respect to each other, are used as inputs to its controller; the same applies for the other two dampers, as indicated schematically in figure 1 . Figure 2 shows the proposed rule base of one of these controllers.

\section{MR DAMPERS' LOCATION OPTIMIZATION SCHEMES}

It is now required to optimize the location of MR dampers such that each of the placed MR dampers is controlled using the previous proposed fuzzy controller; all different possible combinations of damper locations are investigated. Table I shows all possible placement patterns of MR dampers to be studied in order to find the most optimum arrangement. A placement pattern code is assigned for each trial such that it includes the assigned number of included dampers. For example, placement pattern code $(2,3)$ means that only MR dampers 2 and 3 are used (see figure 3 for MR dampers' assigned numbers). For more illustration, placement patterns are divided into three main categories namely, category " $A$ " including patterns with only one MR damper (three patterns), category "B" including patterns with only two MR dampers (three patterns) and category " $C$ " including patterns with three MR dampers (one pattern).

Table II shows all earthquakes that are used in testing the proposed strategies. These earthquakes are chosen to be of variable magnitudes such that the effect of proposed controllers under both low and high-magnitude earthquakes is properly investigated. The earthquakes are chosen such that they are of different properties and frequencies in order to ensure wide range of earthquakes to be used in testing. Figure 4 shows an example of one of the used earthquake time histories, i.e., Kobe Earthquake.

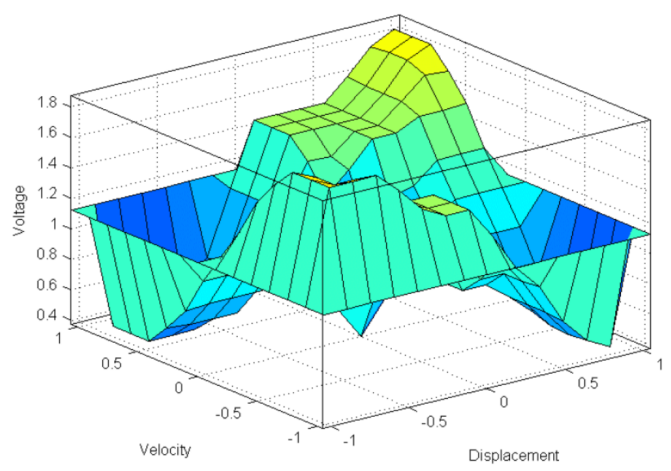

Figure 2. Sample rule base of one of the three parallel fuzzy controllers.

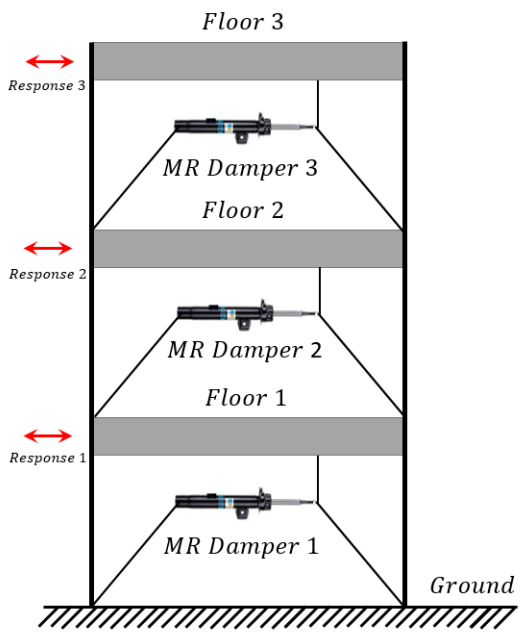

Figure 3. MR dampers' numbering

\section{VALIDATING EARTHQUAKES}

TABLE I.

MR DAMPERS' PLACEMENT PATTERNS

\begin{tabular}{|c|c|c|c|c|}
\hline $\begin{array}{c}\text { Placement } \\
\text { Pattern } \\
\text { Placement } \\
\text { Category }\end{array}$ & $\begin{array}{c}\text { Placement } \\
\text { Pattern } \\
\text { Assigned } \\
\text { Code }\end{array}$ & $\begin{array}{c}\text { MR Damp- } \\
\text { er 1 be- } \\
\text { tween } \\
\text { Ground and } \\
\text { First Floor }\end{array}$ & $\begin{array}{c}\text { MR Damp- } \\
\text { er 2 be- } \\
\text { tween First } \\
\text { and Second } \\
\text { Floors }\end{array}$ & $\begin{array}{c}\text { MR Damper } \\
\text { 3 between } \\
\text { Second and } \\
\text { Third Floors }\end{array}$ \\
\hline \multirow{4}{*}{ A } & 1 & Placed & Not Placed & Not Placed \\
\cline { 2 - 5 } & 2 & Not Placed & Placed & Not Placed \\
\cline { 2 - 5 } & 3 & Not Placed & Not Placed & Placed \\
\cline { 2 - 5 } & 1,2 & Placed & Placed & Not Placed \\
\cline { 2 - 5 } & 1,3 & Placed & Not Placed & Placed \\
\hline \multirow{2}{*}{ C } & $1,2,3$ & Not Placed & Placed & Placed \\
\hline
\end{tabular}

TABLE II.

EARTHQUAKES USED IN VALIDATION OF PROPOSED CONTROLLERS

\begin{tabular}{|c|c|c|c|c|}
\hline$\#$ & Name & Location & $\begin{array}{c}\text { Year of Oc- } \\
\text { currence }\end{array}$ & $\begin{array}{c}\text { Magnitude } \\
\mathbf{( M}_{\mathbf{w}} \mathbf{)}\end{array}$ \\
\hline 1 & Kobe & Japan & 1995 & 6.9 \\
\hline 2 & Kern Country & USA & 1952 & 7.3 \\
\hline 3 & El-Centro & USA-Mexico & 1940 & 6.9 \\
\hline 4 & Trinidad & USA & 1983 & 3.2 \\
\hline 5 & Northridge & USA & 1994 & 6.7 \\
\hline 6 & San Fernando & USA & 1971 & 6.6 \\
\hline 7 & Lander & USA & 1992 & 7.3 \\
\hline 8 & Caldiran & Turkey & 1976 & 7.3 \\
\hline
\end{tabular}

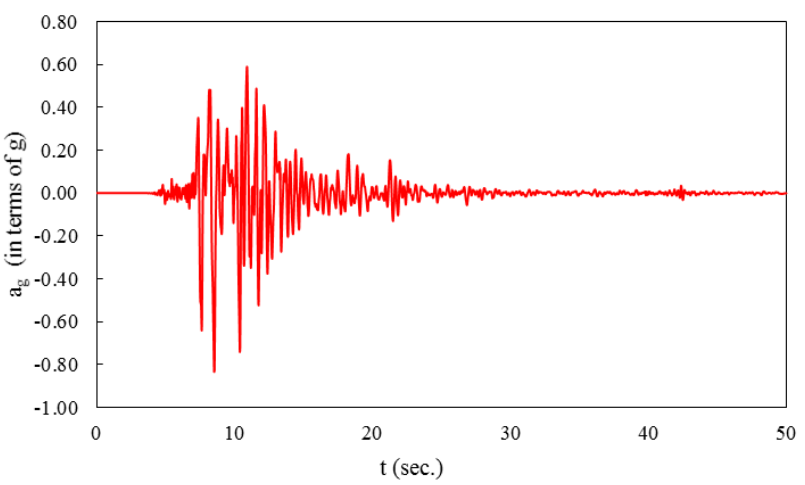

Figure 4. Kobe Earthquake time history 


\section{RESULTS AND DISCUSSION}

The selected earthquake records were employed in testing all proposed MR damper placement patterns.

Based on tables $3 \& 4$, which give controlled response values relative to uncontrolled ones, it can be concluded that:

1. For category A, pattern "1" gives the lowest controlled response with an average displacement $=0.24$ relative to uncontrolled displacement and average acceleration $=0.23$ relative to uncontrolled acceleration.

2. For category B, pattern "1,2" gives the lowest controlled response with an average displacement $=0.21$ relative to uncontrolled displacement and average acceleration $=0.16$ relative to uncontrolled acceleration.

3. Category $\mathrm{C}$ has only one pattern $(1,2,3)$; this pattern gives the lowest controlled response among all patterns with an average displacement $=0.20$ relative to uncontrolled displacement and average acceleration $=0.15$ relative to uncontrolled acceleration.
Based on these conclusions, it is found that placing the three MR dampers such that one damper is placed between each two floors gives the best structural response. The best option for using two dampers is to place the first one between ground and first floor and the second one between first and second floors. The best option for using one MR damper is to place it between ground and first floor. Based on results obtained for each of these previous options, it can be concluded that using two dampers does not result in doubling structural response reduction (as opposed to what may be initially expected); the same is true for using three MR dampers instead of one MR damper. Therefore, it can be recommended to use only one MR damper between ground and first floor as an optimum solution to structural response control; this is true in case the obtained reduction in structural response is acceptable.

Figures 5 to 8 show examples of the results obtained when testing under other earthquakes. It is found that individual results are consistent with average values.

TABLE III.

DISPLACEMENT COMPARISONS (RELATIVE TO UNCONTROLLED RESPONSE) BETWEEN DIFFERENT PLACEMENT PATTERNS

\begin{tabular}{|c|c|c|c|c|c|c|c|c|c|c|}
\hline \multirow{2}{*}{ Category } & \multirow{2}{*}{ Pattern } & \multicolumn{8}{|c|}{ Earthquake ID (refer to table 2) } & \multirow{2}{*}{ Average } \\
\hline & & 1 & 2 & 3 & 4 & 5 & 6 & 7 & 8 & \\
\hline \multirow{3}{*}{ A } & 1 & 0.27 & 0.20 & 0.11 & 0.11 & 0.56 & 0.24 & 0.25 & 0.21 & 0.24 \\
\hline & 2 & 0.35 & 0.37 & 0.25 & 0.19 & 0.66 & 0.42 & 0.40 & 0.37 & 0.38 \\
\hline & 3 & 0.47 & 0.60 & 0.46 & 0.29 & 0.79 & 0.62 & 0.53 & 0.52 & 0.54 \\
\hline \multirow{3}{*}{ B } & 1,2 & 0.24 & 0.15 & 0.09 & 0.09 & 0.54 & 0.20 & 0.19 & 0.14 & 0.21 \\
\hline & 2,3 & 0.33 & 0.31 & 0.21 & 0.17 & 0.63 & 0.36 & 0.37 & 0.34 & 0.34 \\
\hline & 1,3 & 0.25 & 0.18 & 0.10 & 0.10 & 0.55 & 0.23 & 0.23 & 0.18 & 0.23 \\
\hline $\mathrm{C}$ & $1,2,3$ & 0.24 & 0.15 & 0.09 & 0.08 & 0.53 & 0.19 & 0.18 & 0.13 & 0.20 \\
\hline
\end{tabular}

TABLE IV.

ACCELERATION COMPARISONS (RELATIVE TO UNCONTROLLED RESPONSE) BETWEEN DIFFERENT PLACEMENT PATTERNS

\begin{tabular}{|c|c|c|c|c|c|c|c|c|c|c|}
\hline \multirow{2}{*}{ Category } & \multirow{2}{*}{ Pattern } & \multicolumn{8}{|c|}{ Earthquake ID (refer to table 2) } & \multirow{2}{*}{ Average } \\
\hline & & 1 & 2 & 3 & 4 & 5 & 6 & 7 & 8 & \\
\hline \multirow{3}{*}{ A } & 1 & 0.14 & 0.23 & 0.10 & 0.10 & 0.44 & 0.24 & 0.33 & 0.28 & 0.23 \\
\hline & 2 & 0.24 & 0.40 & 0.27 & 0.16 & 0.56 & 0.40 & 0.45 & 0.44 & 0.37 \\
\hline & 3 & 0.39 & 0.61 & 0.48 & 0.26 & 0.73 & 0.61 & 0.55 & 0.54 & 0.52 \\
\hline \multirow{3}{*}{$\mathrm{B}$} & 1,2 & 0.09 & 0.14 & 0.05 & 0.07 & 0.39 & 0.19 & 0.24 & 0.15 & 0.16 \\
\hline & 2,3 & 0.20 & 0.32 & 0.22 & 0.15 & 0.51 & 0.34 & 0.41 & 0.41 & 0.32 \\
\hline & 1,3 & 0.11 & 0.18 & 0.08 & 0.09 & 0.41 & 0.21 & 0.30 & 0.22 & 0.20 \\
\hline $\mathrm{C}$ & $1,2,3$ & 0.08 & 0.11 & 0.05 & 0.06 & 0.37 & 0.17 & 0.20 & 0.13 & 0.15 \\
\hline
\end{tabular}

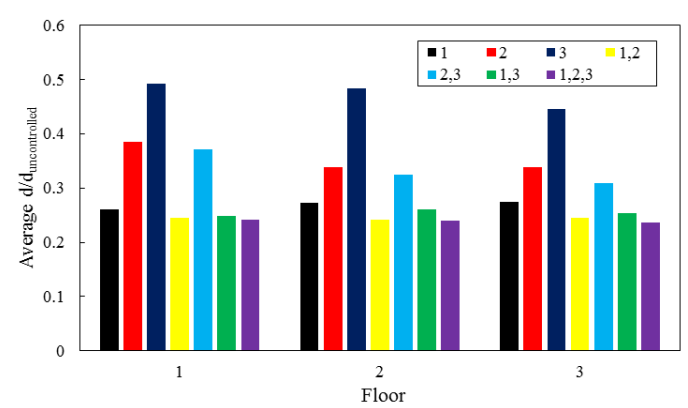

Figure 5. Comparing controlled and uncontrolled displacement at different floors for different dampers' arrangements under Kobe Earthquake.

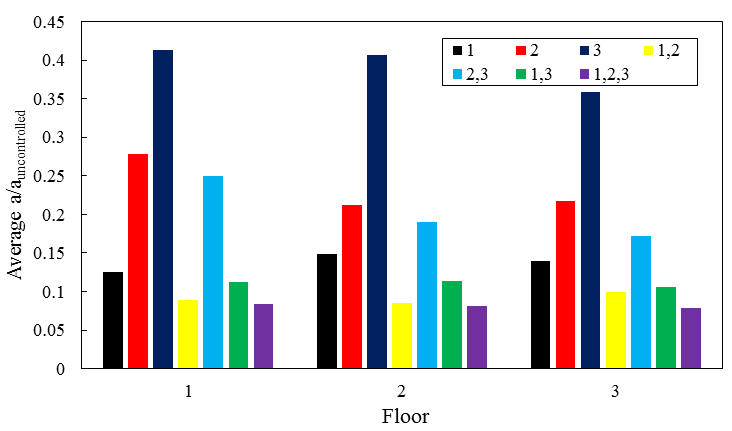

Figure 6. Comparing controlled and uncontrolled acceleration at different floors for different dampers' arrangements under Kobe Earthquake 


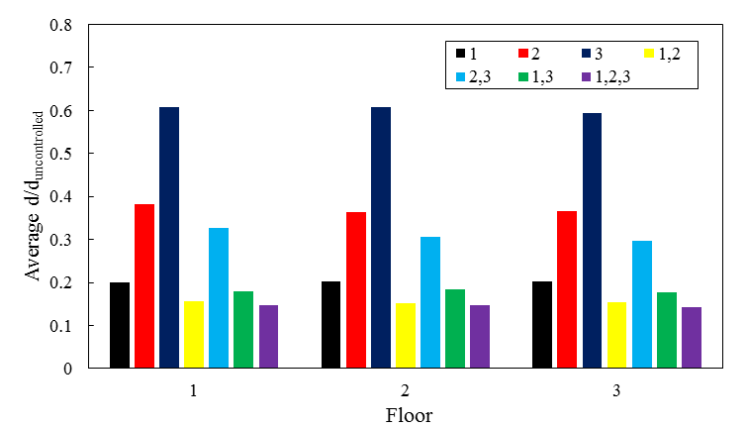

Figure 7. Comparing controlled and uncontrolled displacement at different floors for different dampers' arrangements under Kern Country Earthquake.

\section{SUMMARY AND CONCLUSION}

Fuzzy-controlled MR dampers are considered one of the promising techniques that can be used in structural response control. Much research was done to investigate the possibility of using this technique and to evaluate its efficiency in structural response reduction. Most of the research done in this area was focused on single-degreeof-freedom systems and specific damper configurations for MDOF systems. In this paper, the use of multiple MR dampers to control the response of a three-degree-offreedom benchmark problem is investigated.

In this paper, a comparative analysis was conducted to investigate the optimum location for placing the lowest possible number of fuzzy-controlled MR dampers in a given benchmark problem in order to produce acceptable structural response. All possible placement patterns were investigated for this benchmark problem. It was found that using only one MR damper, placed between ground and first floor, can result in an acceptable behaviour for a 3DOF system. The increase of the number of MR dampers did not result into much reduction. This work is expected to be generalized in order to develop a generic allocation algorithm capable of identifying the optimum number and location of fuzzy-controlled MR dampers for different DOF systems.

\section{REFERENCES}

[1] F. Y. Cheng, H. Jiang and K. Lou, Smart Structures: Innovative Systems for Seismic Response Control, Boca Raton: CRC Press (Taylor and Francis Group), 2008.

[2] B. F. Spencer, S. J. Dyke, M. K. Sain and J. D. Carlson, "Phenomenological Model For Magnetorheological Dampers," Journal of Engineering Mechanics, pp. 230-238, 1997. https://doi.org/10.1061/(ASCE)0733-9399(1997)123:3(230)

[3] K.-M. Choi, S.-W. Cho, H.-J. Jung and I.-W. Lee, "Semi-active Fuzzy Logic Control for Seismic Response Reduction Using Magnetorheological dampers," Earthquake Engineering and Structural Dynamics, pp. 723-736, 2004. https://doi.org/10.1002/eqe.372

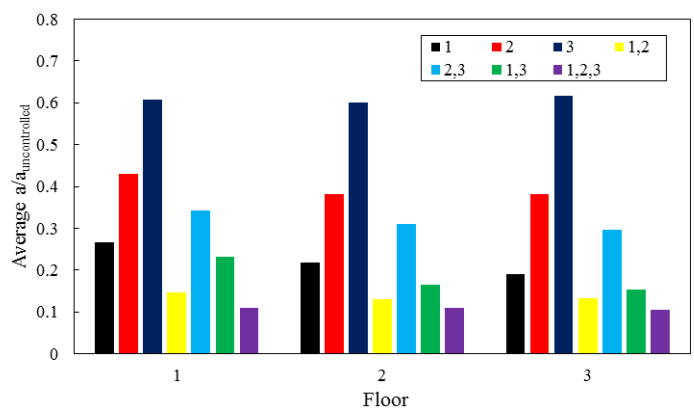

Figure 8. Comparing controlled and uncontrolled acceleration at different floors for different dampers' arrangements under Kern Country Earthquake.

[4] G. Yang, B. F. Spencer Jr., J. D. Carlson and M. K. Sain, "Largescale MR Fluid Dampers: Modelling and Dynamic Performance Consideration," Engineering Structures, pp. 309-323, 2002. https://doi.org/10.1016/S0141-0296(01)00097-9

[5] H. M. Gomes, "Fuzzy Logic for Structural System Control," Latin American Journal of Solids and Structures, pp. 111-129, 2012. https://doi.org/10.1590/S1679-78252012000100006

[6] C. M. D. Wilson, "Effect of Multiple MR Dampers Controlled by fuzzy-based Strategies on Structural Vibration Reduction," Structural Engineering and Mechanics, pp. 1-15, 2012. https://doi.org/10.12989/sem.2012.41.3.349

[7] Y. Liu, F. Gordaninejad, C. Evrensel and G. Hitchcock, "An Experimental Study on Fuzzy Logic Vibration Control of a Bridge using Fail-Safe Magneto-Rheological Fluid Dampers," Smart Structures and Materials, pp. 281-288, 2001.

[8] A. S. Ahlawat and A. Ramaswamy, "Multiobjective Optimal Fuzzy Logic Control System for Response Control of Wind Excited Tall Builidngs," Journal of Engineering Mechanics, pp. 524-530, 2004. https://doi.org/10.1061/(ASCE)07339399(2004)130:4(524)

[9] A. K. Chopra, Dynamics of Structures: Theory and Applications to Earthquake Engineering (4th Edition), Boston: Pearson, 2012.

[10] S. J. Dyke, B. F. Spencer Jr, M. K. Sain and J. D. Carlson, "Modelling and Control o Magneto-rheological Dampers for Seismic Response Reduction," Smart Materials and Structures, pp. 565-575, 1996. https://doi.org/10.1088/0964-1726/5/5/006

[11] M. Battaini, F. Cassciati and L. Faravelli, "Fuzzy Control of Structural Vibration. An Active Mass System Driven by a Fuzzy Controller," Earthquake Engineering and Structural Dynamics, pp. 1267-1276, 1998. https://doi.org/10.1002/(SICI)10969845(1998110)27:11<1267::AID-EQE782>3.0.CO;2-D

\section{AUTHORS}

O. M. M. Elmeligy is a Teaching Assistant, Faculty of Engineering, The British University in Egypt (BUE), ALSherouk City, Cairo, Egypt (omar.elmeligy@bue.edu.eg).

M. H. M. Hassan is a Professor and, Dean of Engineering, The British University in Egypt (BUE), AL-Sherouk City, Cairo, Egypt. (mhassan@bue.edu.eg)

Submitted, 28 October 2016. Published as resubmitted by the authors on 30 November 2016. 